\title{
EFFECTIVENESS OF ORAL AND TOPICAL UNANI FORMULATIONS IN TAQASHSHUR AL-JILD (PSORIASIS): A CASE STUDY
}

\author{
${ }^{1}$ Bhoraniya Abdullah Ismail, ${ }^{1}$ Ansari Umme Ammara Maqbool Ahmad; \\ ${ }^{1}$ Juveria Jabeen and ${ }^{2 *}$ Mohd Afsahul Kalam
}

${ }^{1}$ National Research Institute of Unani Medicine for Skin Disorders (NRIUMSD) AG Colony Road, Opp. ESI Hospital, Erragadda, Hyderabad-500 038

${ }^{2}$ Research Officer Unani, Regional Research Institute of Unani Medicine (RRIUM), Kashmir University, Srinagar

\section{Research Paper}

Received: 27.09.2021

Revised: 08.10.2021

Accepted: 18.10.2021

\section{ABSTRACT}

Taqashshur al-Jild (Psoriasis) is an Autoimmune Inflammatory disease with a worldwide prevalence of about 1.5 -2\%. A 27 years old male patient, approached the outpatient department of the $\mathrm{N}$ ational Research Institute of Unani Medicine for Skin Disorder (NRIUMSD), Hyderabad, with complaints of itching, scaling like dandruff, bleeding, burning of the scalp for one month. The examination of the skin revealed Psoriasis of the scalp. The patient was treated with the Unani regimen comprising of compound formulations Itrifal Shahetra (oral) 5gm, Habb-i-Musaffi Khoon (oral) 2 tablets, Marham Safed Kafoori (Topical), and Roghan Kamela (Topical) over scalp twice daily for 8 weeks days. The patient did not report any adverse effects during and after the treatment. After 8 weeks days of treatment, the whole scalp showed absence of the sign and symptoms of the disease. There was no recurrence of the disease during the next 2 months of post-treatment follow-up. This case report documented the successful treatment and prevention of recurrence of scalp psoriasis through Unani medicines. It concluded that the Unani regimen is effective and safe in the management of scalp psoriasis.

\begin{tabular}{|lll}
\hline No. of Pages: 6 & No. of Tables: 1 & No. of Figures: 1 \\
References: 33
\end{tabular}

Keywords: Psoriasis, Scalp Psoriasis, Taqashshur al-Jild, Unani treatment.

\section{INTRODUCTION}

Psoriasis is a lifelong autoimmune disease characterized by white to red colour patches of abnormal skin with itching which is covered by a silvery scale ${ }^{1}$. The termpsoriasis is derived from the Greek word "psora" meaning itch. Psoriasis affects $1-2 \%$ of the population ${ }^{1}$. The majority of areas are the scalp, fingers and toes, palms, soles, umbilicus, gluteus, underneath the breasts and genitals, elbows, knees, shins, and sacrum $^{2}$. In males and females, the incidence is found equal ${ }^{1}$. Early peak incidence occurs at 22.5 years of age (in children, the mean age of onset is 8 years), and late presents about age 55. The patient had positive family history has an early onset of disease and a more severe form that last for long period.
The pathology of psoriasis can be explained based on the cell kinetics of keratin ocytes. Thus, changes in the germinative layer of the epidermis and inflammatory changes in the dermis, trigger the epidermal changes and leads to psoriasis. In some areas, the thick asbestos-like scales found which shed and reveal a red infiltrated base ${ }^{3}$.

Scalp psoriasis is characterized by a reddish plaque on the scalp, silvery-white scale or dandruff-like flaking, cracking, bleeds (Auspitz sign), itching that can interfere with everyday life and cause loss of sleep, burning sensation or soreness, and temporary hair loss due to scratching the scalp. Once the scalp psoriasis clears, hair usually re-grows ${ }^{1,2,4}$.

*Corresponding author: afsahnium@gmail.com 
Scientific studies state that psoriasis Vulgaris affects around 85 to $90 \%$ of all patients with the disease ${ }^{2}$. It is often precipitated by physical trauma, emotional stress, winter season, infections, medication, and smoking ${ }^{1}$.

In classical Unani literature, psoriasis is termed Taqashshur alJild, it is a common skin disorder characterized by dryness of skin and scale formation just like the scales of a fish ${ }^{5}$.It is aggravated by Akhlat resulting from hiddat and ta'affun-i-dam as well as Safra (impairment of blood and bile) (1,6 $^{1,}$ It occurs due to Ihtiraq-i-Sawda having an irritant nature that destroys the skin and produces intense itching, roughness, and scaling. ${ }^{1,6,7}$

According to Razi and Majusi, an excessive amount of KhiltI-Ghaliz (abnormal sawda) gets accumulated in the skin and hamper its nutrition and function, due to which skin becomes dead and fallout in the form of scales ${ }^{5,8}$. Unani Physicians advise avoiding sour and sweet items in diet ${ }^{1,5,9}$. As far as the treatment is concerned, Unani physicians are successfully treating Taqashshur al-Jild since ancient times by adopting various modes of treatment ${ }^{6,9,10,11}$. The Unani regimen used in this case report showed a promising effect on scalp psoriasis and can be used for effective management of Taqashshur alJild.

\section{MATERIALAND METHODS}

\section{Case report}

A 27 years old male patient visited the O.P.D. of the National Research Institute of Unani Medicine for Skin Disorders (NRIUMSD), Hyderabad on 8/9/2020 with chief complaints of itchy rashes and dandruff-like scaling from the scalp associated with burning sensation even bleeding on itching site. He first noticed a small spot associated with dryness, itching over the head, and dandruff. The symptoms get aggravates by eating chicken and beef. The subject was a non-diabetic, non-hypertensive, non-alcoholic, non-smoker, and had not taken any medicine for any other systemic disease. No relevant history of allergy to any drug and environmental articles was found. Physical and systemic examination was also done. Demographic data such as age, sex, religion, marital status, occupation, and address were recorded. Relevant history of the patients was recorded with regards to their chief complaints with duration, personal history, history, family history, and history of contact with animals were also recorded. He was diagnosed case of psoriasis and previously consulted the dermatologist who was prescribed for application of coal tar and Salicylic Acid scalp lotion and local steroids clobetasol propionate for one month, but he did not have relief completely. The doctor explained to the patient that there is no permanent cure available for Psoriasis, it could only be managed rather slowed by regular use of steroids and other drugs. So, the patient came to NRIUMSD, Hyderabad for further treatment. The patient has been treated on an OPD basis. He was thoroughly interrogated and examined. On General Examination the patient was found alert, oriented, and healthy. The built of the patient was average with fair colour Fitzpatrick 4 (Height: 1.67 m: Weight: 65 kg, BMI: 23 kg/m²). There were no pallor, icterus, and palpable lymph nodes. The vitals were stable (Pulse: 78/minute, Temperature: 97.8 F, Respiratory Rate: 15/minute: Systolic Blood Pressure: 120 $\mathrm{mmHg}$ and Diastolic Blood Pressure: $76 \mathrm{mmHg}$ ) at baseline. Cardio-vascular, respiratory and nervous systems were normal at baseline. On Skin Examination dimension of the lesion was $10 \mathrm{~cm}$ x $14 \mathrm{~cm}$, Erythematous papule, and plaques, flakes like scaling, itching, bleeding spots were found. Auspitz's sign was positive. Written informed consent was taken from the patient. The images of the scalp before and after treatment were taken (Figure-A \& B 1,2,3,4).

\section{Intervention and follow-up}

As per references available in the classical Unani literature an Unani Pharmacopeial medicine Itrifal Shahetra 5gm,Habbi-Musaffi Khoon 2 tablets were given orally with lukewarm water empty stomach twice daily for 8 weeks.The affected area was thoroughly clean with water and dried daily before the application of topical ointment. Marham-i-Safeda Kafoori and Roghan-i-Kamela were applied locally over the scalp (affected area) twice daily for 8 weeks. The dosage of ointment and oil was used according to the size of the lesion. The patient was advised to avoid chicken, beef, and an extra spicy diet and was asked to visit the institute on every two weeks to observe the result of treatment during the entire course. In the beginning, he was allowed to use antihistaminic drugs to reduce the itching during the severe condition, but gradually he was stopped allopathic medicine completely by $2^{\text {nd }}$ week of Unani treatment. Thereafter, improvement was noticed in the signs \& symptoms.

Composition of Itrifal Shahtara (IS): Shahtara (Fumaria officinalis L), 50gm; Post Halela Zard (Terminalia chebula); Halela Kabuli (Terminalia chebula) 50 gm; Sana (Cassia angustifolia) 10gm; Gul-e Surkh (Rosa damascena Mill) 5gm; Maweez Munaqqa (Vitisvinifera) 350 gm. [12]. Composition of Habb-i-Musaffi Khoon (HMK):- Burg-i-Bakayin (Melia azedarach); Burg-I-Neem (Azadirachta indica) 5 gm each; Burg-i-Hina (Lawsonia inermis) 2 gm; Burada Sandal Surkh (Pterocarpus santalinus), Brahmdandi (Tricholepis glaberrima), Post Halela Zard (Chebulic myrobalan), Chaksu (Cassia absus), Sarphuka (Tephrosia purpurea Linn.), Barg-iShahtra (Fumaria indica Pugsley), Tukhm-i-Kishneez Khushk (Coriander sativum Linn), Neel Kanthi (Ajuga bracteosa), Sandal Safaid (Santalum album L), Gul-i-Surkh (Rosa damascena Mill) each 3 gm, Filfil Siyah (Piper nigrum Linn), Zeera Safed (Cuminum cyminum), Gul-i-Kachnal (Bauhinia racemosa Lam) each 1 gm.[12] 
Composition of Marham Safeda Kafuri (MSK):- Mom Safed (white wax)-100gm, Raughan-i-Gul-300ml, Kushta Qalai (Stannum), Murdar Sang (Plumbioxidum), Kafoor (Cinnamomum camphora dried extract)-each 50gm. And Composition of Roghan Kamela (RK): Kamela (Melilotus philippinesis) - 10gm, Roghan Kunjad (Sesamum indicum)$40 \mathrm{gm}$.

\section{OBSERVATIONAND RESULTS}

The patient was a follow-up on the baseline and further at 2, 4,6 , and $8^{\text {th }}$ week and all signs and symptoms were noted (Table-1). PASI (Psoriasis Area Severity Index) score and DQLI (Dermatology Quality of Life Index) scoring were done at baseline and after the $8^{\text {th }}$ week of treatment. At baseline PASI score was 4 (for the scalp only) and DQLI was 16. After the $8^{\text {th }}$ week of treatment, the PASI score was reduced to 1 (for the scalp only) and DQLI was 1 . PASI scoring was done by using formula and DQLI by using standardized questioner. Photograph of scalp psoriasis was taken before starting treatment at baseline (fig. A 1,2,3,4) and after $8^{\text {th }}$ week on completion of the study (fig. B 1,2,3,4,). A significant difference was found. The first follow-up was done after 2 weeks of treatment, patient completely followed the instruction and taken a medicine on time. The subject reported slight relief from itching. The patients experienced marked improvement in psoriasis within few days after the start of this treatment. The itching was relieved within 3 days. Scaling was reduced and areas of normal skin started emerging within few days to weeks. After the $8^{\text {th }}$ week, psoriasis was almost cured without any side effects (figure B $1,2,3,4)$. At baseline all four symptoms were severe but after the $8^{\text {th }}$ week, only mild erythema was present (table- 1 ). Laboratory investigations were carried out to observe any systemic adverse effects of the drug formulation on the body such as $\mathrm{Hb} \%$, total leukocyte count (TLC), differential leukocyte count (DLC), erythrocyte sedimentation rate (ESR), blood sugar, LFT, RFT, urine and stool tests, after $8^{\text {th }}$ weeks of treatment and found within the normal limits. The patient was under observation for 2 months after the treatment and it was found that neither relapsing eruptions nor flare-up of residue lesions occurs.

Table1: Clinical assessment and improved features on subsequent follow-up.

\begin{tabular}{|l|l|c|c|c|c|c|}
\hline $\begin{array}{l}\text { Sr. } \\
\text { No. }\end{array}$ & Clinical features & Baseline & 2nd week & 4th week & 6th weeks & 8th weeks \\
\hline 1 & Itching & ++++ & +++ & ++ & ++ & - \\
\hline 2 & Scaling & ++++ & +++ & ++ & + & - \\
\hline 3 & Erythema & ++++ & +++ & ++ & + & + \\
\hline 4 & Induration & +++ & ++ & + & + & - \\
\hline
\end{tabular}

$++++=$ Severe,$+++=$ moderate to severe,$++=$ moderate, $+=$ mild, $-=$ negative .

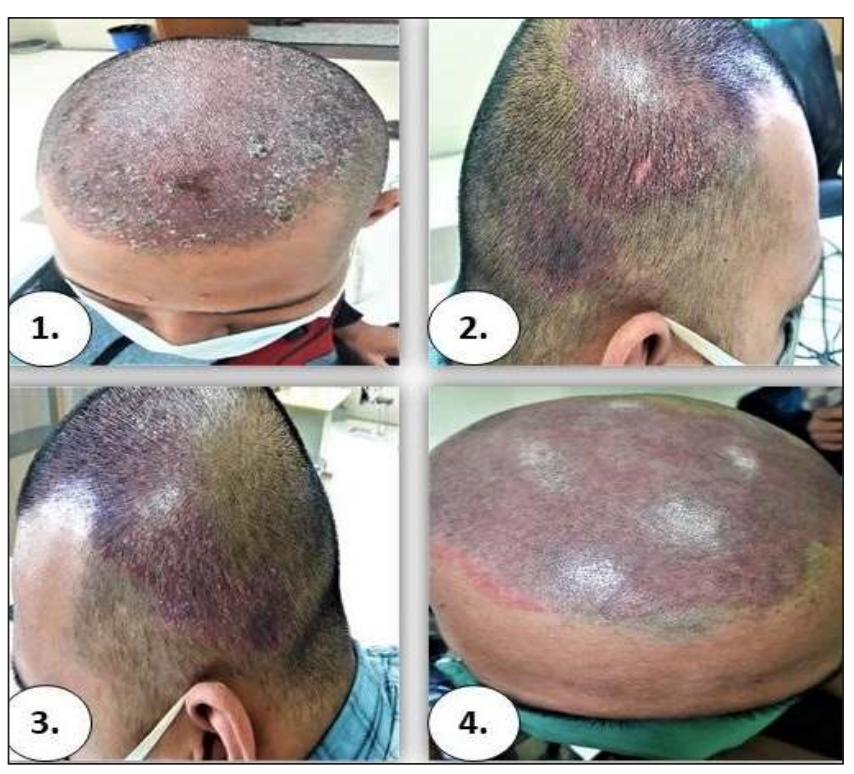

Fig A.

Fig. A1, 2, 3, 4 Before Treatment.

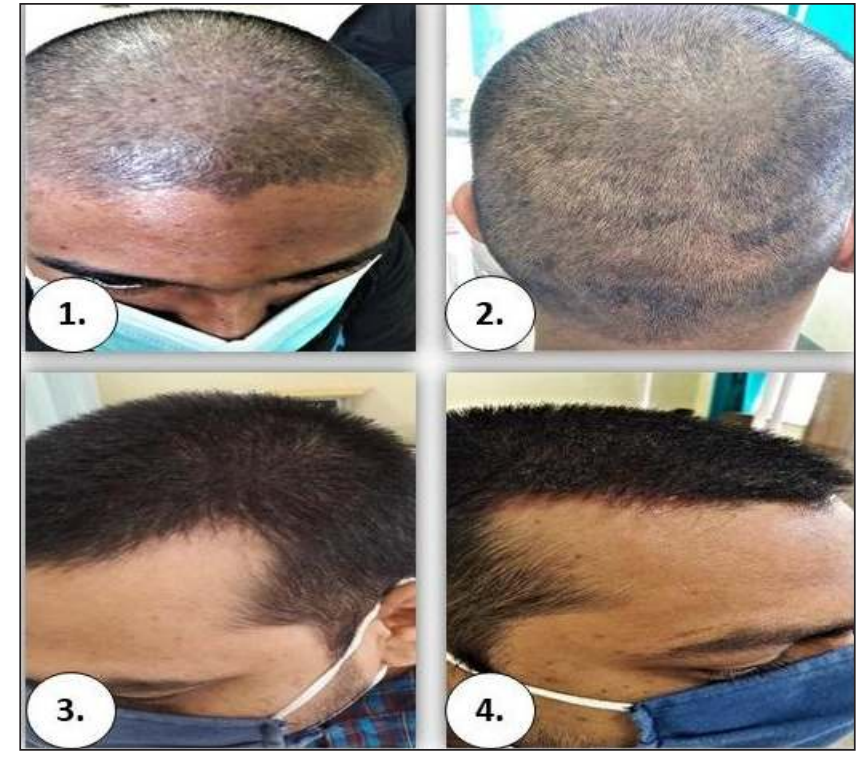

Fig B.

Fig: B1, 2, 3, 4 After Treatment. 


\section{DISCUSSION}

It was observed that the Unani regimen comprising of four formulations IS, HMK MSK, and RK was effective and safe in the management of scalp psoriasis. The effectiveness of the Unani regimen, in this case, might be explained in terms of pharmacological actions of the formulations in the regimen which is mainly due to the blood purifier, antiinflammatory, demulcent, antibacterial, moisturizing, pain sedative, wound healer, and emollient properties present in their ingredients. The affected area was full of scales at baseline but after the $8^{\text {th }}$ week of treatment, the scales were disappeared from the site and the scalp becomes almost normal. There was no complaint of itching and irritation at the time and erythema was decreased.

Itrifal Shahetra is useful to normalize the increased heat of the blood and to cure wounds and boils. Fumaria officinalis one of its ingredients possesses blood purifiers, diuretic, and antipyretic properties [13]. The fumaric acid esters have been used for psoriasis for nearly 30 years. Monoethyl fumarate is the most active metabolite in a German antipsoriatic drug, Fumaderm. A study by Preininger et al. and Dugler et al. reported a significant bactericidal activity against Grampositive organisms like Staphylococcus and Bacillus anthracic [14]. Ahmed et al. carried out a study on various extracts of $C$. Angustifolia show antioxidant and anticancer antimicrobial [15]. Hajhashemi et. al demonstrated that hydroalcoholic extract of $R$. damascena has a potent analgesic effect anti-inflammatory activity in a rat model [16]. Sharif et al. carried out the study, with application of topical water-in-oil (W/O) cream of $2 \%$ grape seed extract, or placebo, on cheek skin, had shown that the antioxidant-rich formulation of grape extract has significant effects on skin melanin levels, elasticity and sebum content when compared to the placebo [17].

Habb-i-Musaffi Khoon contains Bakayan (Melia azedarach) which has antibacterial, fungicidal, antiulcer, antipyretic, anticancer, wound healing activities[11]. Barg-iNeem is mentioned as a blood purifier, antibacterial, cleaner of putrefied wounds in the Unani system of medicine. Pandey et. al study showed patients taking the drug of Neem (Azadirachta indica) leaves in addition to coal tar had shown a quicker and better response in comparison to the placebo group in uncomplicated cases of psoriasis [18]. A study on various extracts of $T$. chebula exhibits ant-bacterial, antioxidant, anti-lipid peroxidation, anti-superoxide radical formation, and free radical scavenging properties (19).

Lone et. al carried out a study on psoriasis Vulgaris showed the test group's overall response was statistically significant, and no response was observed on the control group treated with placebo for the same duration. The improvement in psoriasis may be due to the anti-inflammatory, detergent effects of Sana Makki, improvement in Auspitz sign is the cicatrization effect of Nilatutiya, Murdar sang, hemostatic, taskeen-i-jild (demulsification) effect due to Sandal Surkh, Sandal Safed, and Tahleel-i-Awram (resolution of inflammation) by by Rosa damascena [1]. This agrees with the properties described by Ibn Sina and Najmul Ghani [7,21]. Keshavarz et. al carried out study on Burg-i-Hina revealed that the natural Hina of Iran is more effective than conventional steroids (hydrocortisone) in the healing of the lesions of Diaper Dermatitis in infants [22]. The beneficial effects can be attributed due to the anti-inflammatory, antimicrobial, antibacterial, anti-fungal, immunemodulatory properties of henna [22]. Tephrosia purpurea possess antiulcer, antioxidant, wound healing, antiviral, analgesic, anti-inflammatory, antimicrobial, Mast cell stabilizing potential (anti-allergic), cytotoxic and antipyretic activities [23]. Nisar Ahmad et al. study on Piper nigrum shows different biological activities such as antibacterial, antifungal, analgesic, anti-inflammatory, antimutagenic, anti-metastatic, antioxidative, immunomodulatory [24]. Khare et al. study on various root extracts of Tricholepisglaberima shows antifungal and antiinflammatory activity etc. [25].

Challa et al. proved that methanolic extract of Pterocarpus santalinus Linn. has the highest anti-oxidant property and excellent antimicrobial activity which inhibits bacteria such as E. coli, Staphylococcus aureus, Pseudomonas, etc [26]. Bauhinia racemosa Lam. has anti-bacterial, anti-fungal, antiinflammatory, antioxidant, analgesic, anti-ulcer, andanticancer activities [27]. Studies carried out by Pawar et al on Ajugabracteosa showed anti-inflammatory activity, anticancer activity i.e. cytotoxic against KB cell cultures, and antibacterial activity against gram-positive bacteria [28]. Santalum albumhas anti-inflammatory, anti-mitotic, antiviral, anti-cancerous, anti-ulcer, antifungal, antibacterial activities.[29]

Marham Safed Kafoori is an ointment used as an antiinflammatory, to removes the dead tissues, debris which cleans and heals the wound faster [13]. Mom (beeswax) has anti-inflammatory, analgesic, wound healer, muscle fiber grower, and antipruritic properties. The effect of Mom Zard is because of the presence of oleate esters, palmitoleate, triacontanylpalmitateto cerotic acid, and palmitate [30]. Rahman et al. (2015) carried out a clinical study to compare the efficacy of a herbo-mineral Unani formulation including Murdar Sang (litharge) as an ingredient with benzyl benzoate inscabies. In this clinical study 86.67 and $90 \%$ of patients were cured in the test and control group, with no adverse effects. It was concluded that Murdar Sang was useful in the treatment of scabies [31]. Umair et al. (2015) study on Kushta Qala'i demonstrated significant antimicrobial activity against Streptococcus mutans and Corynebacterium xerosis 
[32]. Cinnamomum camphora has been described as an antiinflammatory, antiseptic, sedative, diaphoretic properties on external use [13]. Najmul Ghani has mentioned in his book Khazinaul Advia that Kafoor possesses many pharmacological activities like antipruritic, cold, antiinflammatory, anti-allergic and useful in vesicle pruritus and burning sensation. [13,21]

In Roghan Kamela, contain Melilotus officinalis L., with anti-inflammatory, anti-swelling, and anti-tumor properties, along with therapeutic effects against haemorrhoids, thrombophlebitis, and varicose veins [33]. Sesamum indicum has anti-inflammatory, antiviral, and analgesic properties. Sesame oil absorbs quickly and penetrates through the tissues and keeps the skin supple and soft which heals and protects areas of mild scrapes, cut, abrasions, and nourishes and feeds the scalp to control dry scalp and dandruff $[13,19]$.

\section{CONCLUSION}

Psoriasis is anautoimmune inflammatory disorder of the skin and scalp. According to the Unani concept, many factors are responsible such as infection and alteration in body humour i.e. Balgham (phlegm) and Sawda (black bile). Effective management is resolving symptoms and countering the recurrence of the disease. The affordability, availability, and side effects of prolonged use of allopathic drugs remain a challenge and concern. The discovery of safer and more effective anti-psoriatic drugs remains an area of active research at present. Excellent tolerance and acceptability were observed in a patient without any reported side effects. These results indicate that Unani compound formulations produce significant improvements in subjective and objective parameters and PASI. Hence, it may be concluded that the above drugs can be used safely and effectively for the treatment of psoriasis. Randomized clinical trials are needed to reveal a new and novel therapeutic option for satisfactory treatment of Psoriasis through Unani classical drugs.

\section{ACKNOWLEDGEMENT}

All authors are thankful to Director, National Research Institute of Unani Medicine for Skin Disorders (NRIUMSD), Hyderabad Dr. Ahmed Minhajuddin for providing the necessary facilities.

\section{Financial support and sponsorship: Nil}

Conflict of Interest: There is no conflict of interest.

\section{REFERENCES}

1. Lone AH, Ahmad $\mathbf{T}$ and Naiyar AH. Clinical evaluation of efficacy of Maj'un Ushba and Roghan Hindi in the management of psoriasis: A Randomized Single-Blind, Placebo-Controlled Study. Journal of Ayurveda \& Integrative Medicine. 2011; 2(1): Pp.26 31.
2. Sowmya C., Lavakumar V, Venkateshan N, Anitha P., Senthilnathan B. Current Trends in Treatment and Management of Psoriasis: An Updated Review. International Research Journal Of Pharmacy.2018; 9. 616.

3. Wolff K., Allen Johnson R. and Saavedra A.P. Psoriasis and Psoriasiform dermatoses, Fitzpatricks Color Atlas and Synopsis of Clinical Dermatology, $7^{\text {th }}$ edition, Mac Graw Hill Publication. New York;2013.p 49-70.

4. KuchekarA.B., Pujari R.R., Kuchekar S.B., Shashikant N.D. and Mule P.M. Psoriasis: A comprehensive review. International Journal of Pharmacy \& life Sciences. 2011;2(6): 857-877.

5. Arzani M.A.Tibb-e-Akbar. Deoband: Faisal Publication; 2002. p. 739.19.

6. Majoosi A.A. Kamil Al Sana'ah. Urdu Translation by Kantoori GH. Vol 1\&2. Lucknow: Matba Munshi Naval Kishore\&, Idara Kitabus Shifa. New Delhi; 2010. p. 431-433.

7. Sina I. Al Qanoon fil' Tib (Arabic)Vol. 4. Jamia Hamdard. New Delhi; 1999. p.187-8.

8. Razi AMBZ. KitabulFakhir Fit Tib (Arabic). Part-1(1), Central Council for Research in Unani Medicine. New Delhi; 2005. 28, 46.

9. Hubal I. Kitabul Mukhtarat Fit Tib (Urdu translation). Vol 2.Central Council for Research in Unani Medicine. New Delhi; 2005.Pp 83,189-190.

10. Razi AMBZ. Al-Hawi Fit Tib (Urdu translation by Hakeem MY Siddiqui). Vol-23, Saba Publishers. Aligarh; 1994.pp 61-62.

11. Shamim. Bakayan (Melia azedarach) pharmacological actions, therapeutic uses and phytochemistry: A review. The Pharma Innovation Journal. 2019;8: 86-92.

12. Anonymous. National Formulary of Unani Medicine. Part I. Central Council for Research in Unani Medicine, New 2006, Pp 96, 224.

13. Tariq SSH. Clinical Efficacy of Unani Formulations in Psoriasis (Da-us-Sadaf): a Case Report. Int $J$ Res Dermatol. 2020;6:804-8.

14. Aghajanshakeri S., Babaeimarzangou S.S., Anousheh D., Mikaili P. Ethno-botanical, bioactivities and Medicinal Mysteries of Fumaria officinalis (Common Fumitory), J Pharm Biomed Sci. 2015; 5(11): 857-862.

15. Ahmed SI, Hayat MQ, Tahir M, Mansoor Q, Ismail M, Keck K, Bates RB. Pharmacologically active flavonoids from the anticancer, antioxidant and 
antimicrobial extracts of Cassia angustifolia Vahl. BMC Complement Altern Med. 2016 Nov 11;16(1):460.

16. Valiollah Hajhashemia, Alireza Ghannadi, Mohammad Hajiloo, Iranian. Analgesic and Antiinflammatory Effects of Rosa damascena hydroalcoholic extract and its Essential Oil in Animal Models. Journal of Pharmaceutical Research. 2010;9 (2): 163-168.

17. Sharif A., Akhtar N., Khan M.S., Menaa A., Menaa B., Khan BA, Menaa F. Formulation and evaluation on human skin of a water-in-oil emulsion containing Muscat hamburg black grape seed extract. Int J Cosmet Sci.2015Apr;37(2):253-8.

18. Pandey SS, Jha AK, Kaur V. Aqueous extract of neem leaves in treatment of Psoriasis vulgaris. Indian $J$ Dermatol Venereol Leprol. 1994;60:63-67.

19. Raghavan K., Kumar A., Pal A., Khanum F., Bawa A.S. Nutritional, Medicinal and Industrial Uses of Sesame (Sesamum indicum L.) Seeds-An Overview. Agricconspec Sci. 2010; 75(4): 159-68.

20. Chen X, Sun F, Ma L et al. In vitro evaluation on the antioxidant capacity of tri-ethylchebulate, an aglycone from Terminalia chebula Retz fruit. Indian Journal of Pharmacol. 2011; 43(3): 6.

21. Ghani HN. Khazainul Advia. Sheikh Basheer and Sons. Lahore; YNM.

22. Keshavarz A., Zeinaloo A.A., Mahram M., Mohammadi N., Sadeghpour O., Maleki M.R. Efficacy of Traditional Medicine Product Henna and Hydrocortisone on Diaper Dermatitis in Infants. Iran Red Crescent Med J. 2016; 18(5): 22, e24809.

23. Ansari, Mushir and Jahan N. Tephrosiapurpurea (L.) Pers. (Sarphuka, Wild Indigo): An important drug of Unani system of medicine. 2019; 6(2): 61-69.

24. Ahmad Nisar, FazalHina, Abbasi Bilal \& Farooq Shahid, Ali Mohammad and Khan Mubarak. Biological role of Piper nigrum L. (Black pepper): A review. Asian Pacific Journal of Tropical Biomedicine. 2012. 2. 10.1016/S2221-1691(12)60524-3.
25. Khare E, Ghosh S, Sharma A. The versatility of Tricholepisglaberrima (Brahmadandi): An Overview Nayanika, Environment Conservation Journal. 2020; 21 (3): 149-154.

26 Chandra Sekhar C., Lokesh T., Devanna N.N,. Varadacharyulu C.H. Phytochemical and AntiMicrobial Study of Pterocarpus Santalinus Linn Heartwood, e RJLBPCS. 2019; 5(3): 453.

27. Kesavan D. \& Chinnachamy C. Pharmacological Properties of Bauhinia Racemosa Lam. CiiT International Journal of Biometrics and Bioinformatics. 2011;3. 520-522.

28. Akriti Pala, Mayank Jadona Y.K., Katarea, P.K. Singoura H., Rajakb P.K., Chaurasiyaa UK. Patila and Pawara R.S. Ajugabracteosa wall: A review on its ethnopharmacological and phytochemical studies, Der Pharmacia Sinica. 2011; 2(2):1-10.

29. Kumar Rakesh, Anjum Nishat and Tripathi Yogesh. Phytochemistry and Pharmacology of Santalum album L.: A Review. World Journal of Pharmaceutical Research. 2015; 4. 1842-1876.

30. Khan MS, Lari QH and Khan MA. Therapeutic Uses of Mom Zard (Beewax) in Unani System of Medicine. Int J Pharm Bio-Sci. 2016; 3(1)1-4.

31. Rahman J, Farooqi JA, Sultana A, Rahman K and Rahman A. Clinical Efficacy of a Herbo-mineral Unani Formulation in Scabies: an Open-label Randomized Clinical efficacy of a herbo-mineral Unani formulation in scabies, Orient Pharm Exp Med, 2015; 15:173-181.

32. Umair SM, Rehman S, Tajuddin, Siddiqi KS and Nami SAA. Nanotization, Characterization and In-Vitro Activity of Kushta-e-Qalai (Tin Calx): A Traditional Unani Medicine of India. Pharm Anal Acta, 2015; 6: 388.

33. Pall Yu-Ting Liu, Pei-Han Gong, Feng-Qin Xiao, Shuai Shao, Da-Qing Zhao, Ming-Ming Yan, et al. Chemical Constituents and Antioxidant, AntiInflammatory and Anti-Tumor Activities of Melilotus officinalis (Linn.), Molecules 2018, 23, 271; doi:10.3390/molecules23020271). 